\title{
EPIDEMIOLOGIA E MANEJO DO MOFO CINZENTO DA MAMONA
}

\author{
MORAES, Wanderson Bucker ${ }^{1,4}$ \\ JESUS JUNIOR, Waldir Cintra de ${ }^{1,5}$ \\ MORAES, Willian Bucker ${ }^{2}$ \\ TOMAZ, Marcelo Antonio ${ }^{1}$ \\ SOUZA, Antônio Fernando de ${ }^{3}$ \\ AMARAL, José Francisco Teixeira do ${ }^{1}$ \\ PEIXOTO, Leonardo de Azevedo ${ }^{1}$
}

RESUMO: A cultura da mamona tem demonstrado grande importância para produção de biodiesel, principalmente pela qualidade de seu óleo e por não competir com a alimentação humana. O cultivo da mamona está sujeito ao ataque de inúmeros patógenos, dentre os quais, destaca-se o mofo cinzento causado por Amphobotrys ricini. Este afeta as inflorescências, os cachos e as sementes, reduzindo assim a produção e o teor de óleo nos frutos. As condições climáticas favoráveis para ocorrência do mofo cinzento no Brasil e a intensificação do cultivo da mamona, com a introdução de cultivares altamente produtivas, tem contribuído para o aumento dos danos causados por esta doença. O controle do mofo cinzento tem como base a utilização de medidas preventivas, uma vez que medidas curativas não são eficazes ou até o momento estão indisponíveis. $\mathrm{O}$ uso de cultivares resistentes, sementes sadias, rotação de culturas, eliminação de restos culturais, tratamento químico das sementes são algumas das medidas que podem ser empregadas no manejo da $A$. ricini. Contudo, mais estudos devem ser realizados para o entendimento do patossistema mamona - A. ricini a fim de auxiliar o desenvolvimento e a incorporação de novas técnicas de manejo para esta doença, bem como aprimorar as existentes.

Palavras chave: Ricinus communis. Amphobotrys ricini. Epidemiologia. Manejo integrado de doença.

\section{EPIDEMIOLOGY AND MANAGEMENT OF GRAY MOLD OF CASTOR BEAN}

SUMMARY: The castor bean crop has shown great importance for the production of biodiesel, mainly for the quality of its oil and not compete with food. The cultivation of castor oil is subject to attack by numerous pathogens, among which stands out the gray mold caused by Amphobotrys ricini. This affects the inflorescences, clusters and seeds, thus reducing production and oil content in fruits. Favourable climatic conditions for the occurrence of gray mold in Brazil and the intensification of cultivation of castor beans, has helped to increase the damage caused by this disease. The control of gray mold is based on the use of preventive measures, since curative measures are not effective or are unavailable until now. The use of resistant varieties, healthy seed, crop

\footnotetext{
${ }^{1}$ Universidade Federal do Espírito Santo, Centro de Ciência Agrárias, Departamento de produção vegetal, Alto universitário s/n, 29500-000, Alegre, ES, Brasil. E-

mail:wbucker@yahoo.com.br; wcintra@cca.ufes.br; tomazamarcelo@yahoo.com.br; jftamaral@yahoo.com.br; leonardopeixotoagro@hotmail.com

${ }^{2}$ Universidade Estadual Paulista Júlio de Mesquita Filho, Faculdade de Ciências Agronômicas de Botucatu, Departamento de Defesa Fitossanitária, Fazenda Experimental Lageado, Lageado, CEP 18610-307, Botucatu, SP, Brasil. E-mail: moraeswb@ hotmail.com

${ }^{3}$ Instituto Federal de Educação, Ciência e Tecnologia do Espírito Santo, Campus Santa Teresa, Rodovia ES 080, Km 21, São João de Petrópolis, CEP 29650-000, Santa Teresa, ES, Brasil. E-mail: antoniofs @ifes.edu.br

${ }^{4}$ Bolsista de Iniciação Científica do CNPq

${ }^{5}$ Bolsista de Produtividade em Pesquisa do CNPq
} 
rotation, elimination of crop residues, the chemical treatment are among measures that can be employed in the management of $A$. ricini. Additionally, zoning areas of climate risk of occurrence of gray mold is a promising alternative to be implemented in the program management of this disease. However, more studies are needed to understand the pathosystem castor - A. ricini to assist the development and adoption of new management techniques for this disease, as well as improve existing ones.

Keywords: Ricinus communis. Amphobotrys ricini Epidemiology. Disease management strategies.

\section{INTRODUÇÃO}

A mamona (Ricinus communis L.) é uma planta oleaginosa, com a singularidade de não possuir óleo comestível e produzir um lipídio natural que é solúvel em álcool (FREIRE et al., 2001). O óleo é o produto mais importante da mamona, principalmente para os agricultores que exploram a cultura comercialmente; possuindo teor na semente de $35 \%$ a $55 \%$, sendo o padrão comercial 44\% (FREIRE et al., 2006). O seu óleo é um dos melhores produtos para produção de biodiesel em função das suas características particulares, tais como maior densidade, solubilidade em álcool, e cerca de 5\% de oxigênio a mais na molécula (BELTRÃO et al., 2003).

A produção da mamona é limitada por vários fatores, sendo as doenças um dos principais que afetam a cultura. O cultivo da mamona está sujeito ao ataque de inúmeros patógenos, dentre os quais, destaca-se o mofo cinzento causado por Amphobotrys ricini, considerada como a doença mais destrutiva da cultura. O mofo cinzento afeta as inflorescências, os cachos e as sementes, reduzindo a produção e o teor de óleo nos frutos, podendo inclusive levar à perda total da produção caso medidas de controle não sejam tomadas no início do desenvolvimento da doença (LIMA et al., 2001).

O A. ricini ocorre nas maiores regiões produtoras de mamona do País, principalmente onde as condições climáticas são favoráveis ao seu desenvolvimento e disseminação. Esta doença vem se destacando com a intensificação da exploração comercial da mamona. Embora a tática mais aceitável de manejo da $A$. ricini encontra-se baseada no emprego de cultivares resistentes, é de extrema importância conhecer alguns atributos inerentes ao seu patossistema, de modo a implementar técnicas alternativas de manejo para esta doença, como plantios em áreas desfavoráveis ao patógeno e o uso de fungicidas, mediante ao registro prévio destes no Ministério da Agricultura. 


\section{MOFO CINZENTO DA MAMONA (Amphobotrys ricini)}

O mofo cinzento foi observado pela primeira vez em 1918, infectando as partes florais e cápsulas das sementes nos Estados Unidos (EUA), particularmente no estado da Flórida. Foi observado que a doença apresentava um desenvolvimento gradual durante a estação de cultivo, passando de algumas infecções esporádicas nos frutos para grande capacidade de dispersão e destruição dos racemos. O cultivo com mamona na região sul do EUA teve resultados catastróficos, devido às condições ambientais favoráveis ao desenvolvimento do patógeno (GODFREY, 1923).

O Brasil, o mofo cinzento foi constatado em 1932, no Estado de São Paulo, e atualmente é considerada a principal doença em várias regiões produtoras, ocasionando perdas significativas na produção (LIMA et al., 2001). Sob condições climáticas favoráveis, promove rápida e completa destruição dos cachos, causando grandes prejuízos à produção. Os problemas com o mofo cinzento agravaram-se a partir da intensificação do cultivo da mamona e da introdução de cultivares mais produtivas, porém nem sempre resistentes à doença.

\section{Etiologia}

O mofo cinzento é causado pelo fungo Amphobotrys ricini, cuja forma teleomórfica a Botryotinia ricini (Godfrey) Whetzel pertencente à classe dos Ascomycetes, ordem Helotiales e família Sclerotiniaceae (LIMA et al., 2001). Inicialmente, o fungo foi descrito como Botrytis ricini Godfrey e o seu teleomorfo foi denominado de Sclerotinia ricini Godfrey. O nome do gênero foi modificado por Whetzel para Botryotinia e Hennebert estabeleceu o novo gênero Amphobotrys para agrupar a forma conidial semelhante a Botrytis ricini. O gênero Amphobotrys possui uma única espécie típica, A. ricini (HOLCOMB et al., 1989).

A formação de escleródios, relatada somente em condições de laboratório, deve ocorrer no campo durante os meses mais frios. As colônias de A. ricini são efusas, tornandose branco acinzentado para castanho, com hifas hialinas, septadas e ramificadas. O conidióforo é ereto, único e grande com haste cilíndrica, de coloração marrom claro, septada. Próximo à metade da altura o conidiófora bifurca-se formando um ângulo largo, com ramificações quase simétricas, longas e cilíndricas, bifurcando-se repetidamente a intervalos curtos para produzir grupos aos pares, globosos, inflados de células conidiogênicas terminais. Cada conídio desenvolve-se simultaneamente em pedicelos curtos, que entram em colapso na maturidade. Os conídios são regularmente globosos, sub-hialinos para castanho, lisos, produzindo uma discreta ornamentação no septo basal, com dimensões de 6 a $12 \mu \mathrm{m}$, (HENNEBERT, 1973). Culturas do fungo são obtidas facilmente em meio de cultura padrão. 
O estado perfeito é desconhecido em meio de cultura (HENNEBERT, 1973).

\section{Sintomatologia}

O fungo ataca as inflorescências e os frutos em qualquer fase de desenvolvimento. Inicialmente, surgem manchas azuladas com exsudação amarela nas áreas afetadas. Se as condições ambientais forem favoráveis, o fungo continua a colonização, podendo cobrir grandes extensões dos cachos com uma massa micelial olivácea de aspecto mofoso (Figura 1.). Quando os cachos afetados são agitados, ocorre a liberação de grande quantidade de esporos, facilmente dispersados pelo vento e constituindo como inóculo para novas infecções (GODFREY, 1923). Em consequência, ocorre completa deterioração das inflorescências e dos frutos e os cachos tornam-se frouxos e com as cápsulas pendentes. As sementes das cápsulas afetadas apresentam desde redução no teor de óleo até chochamento completo, dependendo do estágio em que ocorreu a infecção (MASSOLA JR.; BEDENDO, 2005). Infecções em folhas e hastes também podem ocorrer, entretanto são pouco frequentes.

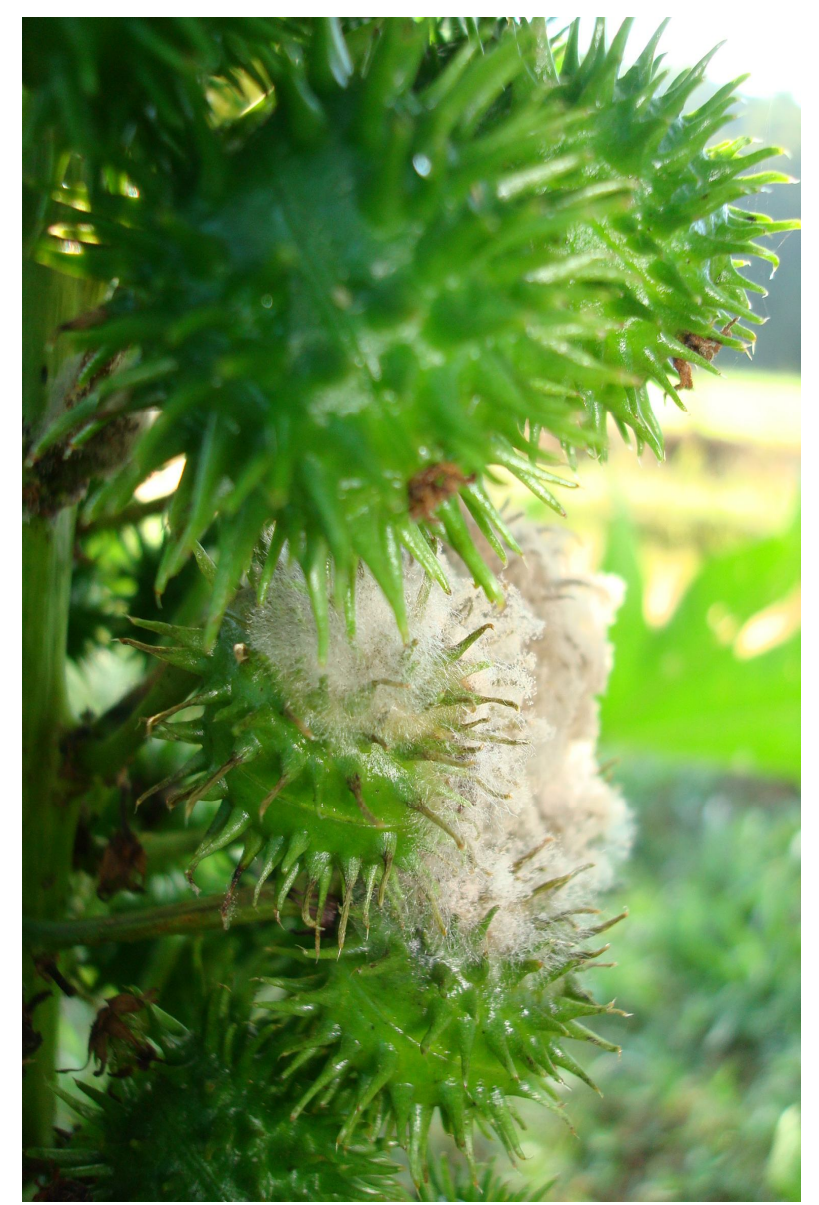

Figura 1. Sintomas de mofo cinzento (Amphobotrys ricini) em frutos de mamona, evidenciando a presença de hifas e corpos de frutificação do patógeno (conídios). 


\section{Epidemiologia}

O mofo cinzento é particularmente destrutivo quando o período de floração ou frutificação de uma cultivar suscetível coincide com as condições climáticas ótimas para o desenvolvimento da doença, ou seja, alta umidade e temperaturas em torno de $25{ }^{\circ} \mathrm{C}$ (MELHORANÇA; STAUT, 2005). Nas condições de campo a temperatura influência o progresso da doença, sendo que em locais com temperatura máxima diária inferior $22{ }^{\circ} \mathrm{C}$ a doença não progrediu (ARAÚJO et al., 2007).

A. ricini não é capaz de penetrar no hospedeiro através de aberturas naturais. $\mathrm{O}$ fungo depende de enzimas hidrolíticas, provavelmente enzimas pécticas e celulolíticas, para decompor os tecidos e iniciar o processo de infecção. O processo de infecção em cápsula de mamona é estimulado pela grande quantidade de açúcares solúveis, notadamente glicose e frutose (ORELLANA ; THOMAS, 1962).

A disseminação dos esporos é feita principalmente pelo vento, porém alguns insetos, atraídos pela grande exsudação de néctar nas flores, também desempenham importante papel na disseminação do fungo. A sobrevivência de A. ricini entre as estações de cultivo é assegurada pela produção de escleródios no solo ou em restos de cultura como micélio ou escleródios, em sementes contaminadas, bem como em espécies espontâneas (MASSOLA JR.; BENDENDO, 2005).

\section{Manejo da Doença}

O controle do mofo cinzento tem como base medidas preventivas, uma vez que medidas curativas são poucos eficazes ou estão indisponíveis até o momento. Considerando que não existem medidas curativas eficazes para o controle do mofo cinzento da mamona principalmente pela ausência de fungicidas registrados no Ministério da Agricultura e do Abastecimento (MAPA, 2009), a adoção de medidas preventivas deve constituir a principal estratégia de controle desta doença. O uso de cultivares resistentes, sementes sadias, rotação de culturas, eliminação de restos culturais, e o tratamento de sementes são algumas das táticas que podem ser empregadas no manejo da A. ricini.

As estratégias de manejo do mofo cinzento da mamoneira devem ser implementadas visando o retardamento do início da epidemia e/ou a redução da taxa de progresso da doença (MELHORANÇA; STAUT, 2005). Escolha de regiões onde as condições climáticas sejam desfavoráveis ao desenvolvimento de epidemias, combinadas com a adoção de métodos culturais como a rotação de cultura, eliminação de mamoneiras espontâneas e dos restos culturais, utilização de maiores espaçamentos e podas, contribuem para reduzir a quantidade 
de inóculo do patógeno em áreas cultivadas (LIMA et al., 2001).

O controle químico deve ser realizado após o aparecimento dos sintomas inicias da doença sendo que esta tática visa à proteção das inflorescências e dos cachos jovens e à redução do inóculo nos cachos velhos, uma vez que frutos já formados têm menor suscetibilidade à doença ( ARAÚJO et al., 2007). Araújo et al. (2007) observaram que a aplicação de fungicida sistêmico após o surgimento dos primeiros sintomas em região de clima favorável ao desenvolvimento do mofo cinzento, retardou o início da epidemia e reduziu o progresso da doença; entretanto, até o momento não existe fungicidas registrados para a cultura.

A utilização de cultivares resistente é o método mais eficaz e desejável para o manejo do mofo cinzento, entretanto informações sobre o nível de resistência das cultivares ainda são escassas (FREIRE et al., 2001; LIMA et al., 2001; MASSOLA JR. ; BENDENDO, 2005). Sabe-se que algumas características da planta influenciam sua reação a A. ricini. Assim, por exemplo, as cultivares anãs e com inflorescências compactas, apesar de permitirem colheita mecanizada, tem se mostrado mais suscetíveis à doença devido à formação de um microclima favorável no interior das copas. Por outro lado, as cultivares que possuem as cápsulas sem acúleos são mais resistentes em condições de campo. Estudo realizado nas condições do agreste de Pernambuco revelou como promissoras as cultivares MP AI T63/6, Canela de Juriti, Sipeal 28, Sipeal 04, CNPA SM1, Sangue de Boi, LC 5116 e Sipeal 09, enquanto que Poblacion Chajari, Baker 415-9 e Baker Hibrid 72 comportaram-se como as mais suscetíveis (MASSOLA JR. ; BENDENDO, 2005). Lima ; Soares (1990), estudando a resistência de 15 genótipos de mamona ao mofo cinzento, verificou que os genótipos mais resistentes foram MP AI T 63/6, Canela de Juriti, SIPEAL 04, CNPA SM1, Sangue de Boi, LC 5116 e SIPEAL 09.

Batista et al. (1998) avaliando 25 acessos do banco de germoplasma da Embrapa, constatou que os acessos 69 e 58 mostraram ser mais suscetíveis a doença que os acessos 91 , 57, 83 e 65. Os acessos com racemos mais compactos mostravam-se mais vulneráveis à incidência de mofo cinzento. A avaliação da intensidade da doença em cinco cultivares de mamona (Guarany, AI Guarany 2002, Mirante 10, Lyra Hibrido e Hibrido 2) sob diferentes arranjos populacionais, demostrou que todas as cultivares comportaram-se como suscetíveis, com variação de incidência de frutos infectados de 25\% a 48\% (FERNANDES et al., 2006).

O tratamento químico de sementes de mamona, visando à eliminação ou redução do inóculo de $A$. ricini, é uma medida que previne a introdução do patógeno via sementes em novas áreas de cultivo. Poletine et al. (2006) avaliando a influência do uso de fungicidas no 
tratamento de sementes de mamona em dois genótipos, concluíram que o tratamento das sementes com os fungicidas captan (160 g i.a. $100 \mathrm{Kg}^{-1}$ semente), thiram+carbendazim $\left(140+70 \mathrm{ml}\right.$ i.a. $100 \mathrm{Kg}^{-1}$ semente), mancozeb+carbendazin (200 g+70 ml i.a. $100 \mathrm{Kg}^{-1}$ semente) e carboxin+thiram ( $250 \mathrm{ml}$ i.a. $100 \mathrm{Kg}^{-1}$ semente) proporcionou os menores valores de severidade do mofo cinzento, para ambos os genótipos estudados. A mistura carboxyn + thiram propiciou as plantas maior produtividade entre os produtos avaliados.

$\mathrm{O}$ uso e manejo dos nutrientes de forma equilibrada têm demonstrado ser uma alternativa eficiente no controle de determinadas doenças de plantas, havendo, contudo a necessidade da realização de mais pesquisas, procurando conhecer as exigências nutricionais, comportamento das doenças em diferentes níveis, fontes e combinação de nutrientes (DATNOFF et al., 2007). A deficiência, excesso ou desequilíbrio nas combinações de elementos nutricionais pode influenciar a reação das plantas à infecção por patógenos de forma a aumentar o nível de defesa ou favorecer a ocorrência de doenças (BALARDINI et al., 2006). Silva (2007) avaliando a influência da adubação fosfatada na intensidade do mofo cinzento nas cultivares de mamoneira Nordestina e Paraguaçu, observou que a adubação fosfatada influenciou significativamente a intensidade do mofo cinzento. As doses máximas de fósforo determinadas para se obter a mínima intensidade de doença, foram de 68,48 e $64,39 \mathrm{~kg} / \mathrm{ha}$ para as cultivares Nordestina e Paraguaçu, respectivamente.

\section{Mapeamento de áreas de risco para mofo cinzento da mamona}

Considerando que não existem medidas curativas eficazes para o controle do mofo cinzento da mamona principalmente pela ausência de fungicidas registrados no Ministério da Agricultura e do Abastecimento (MAPA, 2009), a adoção de medidas preventivas deve constituir a principal estratégia de manejo da doença. Desta forma é de extrema importância conhecer alguns atributos inerentes ao patossistema A. Ricini/mamona, de modo a implementar técnicas alternativas de manejo para esta doença, tais como o plantio em áreas/épocas desfavoráveis ao patógeno. Com este objetivo MORAES et al. (2009) realizaram o mapeamento espaço-temporal das áreas mais propensas ao desenvolvimento do mofo cinzento no Brasil, definindo as condições adequadas para o patógeno se estabelecer e desenvolver, que podem servir como subsídio ao desenvolvimento de sistemas de previsões.

As variáveis climáticas temperatura média do ar (Tm) e umidade relativa do ar (RH), utilizadas para estruturação do banco de dados, são consideradas as mais importantes para o estabelecimento e desenvolvimento do mofo cinzento. Os dados espacializados médios mensais das variáveis climáticas ( Tm e RH ) foram originários de estudos conduzidos pelo 
Climate Research Unit (C.R.U.) da University of East Anglia, Inglaterra, a partir do trabalho de NEW et al. (2002). Estes dados são referentes ao período de 1961 a 1990, disponibilizados gratuitamente no website do C.R.U., no endereço eletrônico http://www.cru.uea.ac.uk, sob o formato matricial (grid), com células de 10’x10' de latitude e longitude.

Com base nas diferentes classes de aptidão para o estabelecimento do mofo cinzento (Tabela 1), foi realizado o mapeamento das áreas brasileiras enquadradas em cada uma das classes de favorabilidade a ocorrência do mofo cinzento.

Tabela 1. Classes de favorabilidade para o estabelecimento e desenvolvimento do Amphobotrys ricini, agente causal do mofo cinzento da mamona, de acordo com características climáticas.

\begin{tabular}{ccccc}
\hline Classe & Descrição & Faixa de Tm do ar & Faixa de RH do ar \\
\hline 1 & Altamente favorável & $20^{\circ} \mathrm{C}$ a $25^{\circ} \mathrm{C}$ & e & superior a $80 \%$ \\
\hline \multirow{2}{*}{ Favorável } & $15^{\circ} \mathrm{C}$ a $20^{\circ} \mathrm{C}$ & & \\
& & ou & & superior a $80 \%$ \\
& $25^{\circ} \mathrm{C}$ a $30^{\circ} \mathrm{C}$ & & \\
\hline 3 & Relativamente favorável & $15^{\circ} \mathrm{C} \mathrm{a} 30^{\circ} \mathrm{C}$ & e & $70 \%$ a $80 \%$ \\
\hline 4 & Desfavorável & $<15^{\circ} \mathrm{C}$ ou $>30^{\circ} \mathrm{C}$ & e & inferior a $70 \%$
\end{tabular}

Fonte: Moraes et al. (2009).

Utilizando-se técnicas de geoprocessamento foram confeccionados 12 mapas para a representação das áreas de favorabilidade climática a ocorrência do mofo cinzento da mamona no Brasil (Figura 1). Com base nos resultados foi verificado que as áreas classificadas como altamente favoráveis ao desenvolvimento do mofo cinzento concentram-se na região Norte, nos estados do Tocantins, Mato Grosso, Minas Gerais e no litoral das regiões nordeste e sudeste do Brasil. As condições climáticas presentes nestas regiões podem favorecer o desenvolvimento da doença e inviabilizar o plantio da mamona nestas áreas em determinados meses do ano, devido à alta capacidade de destruição dos cachos por este patógeno sob condições ambientais favoráveis e a inexistência de medidas de controle químicos curativos eficazes. 


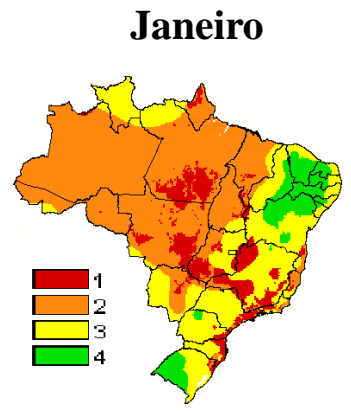

Abril

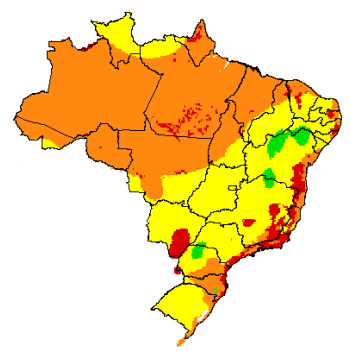

Julho

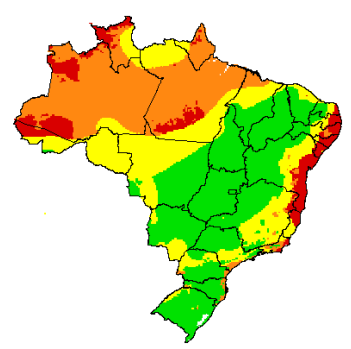

Outubro

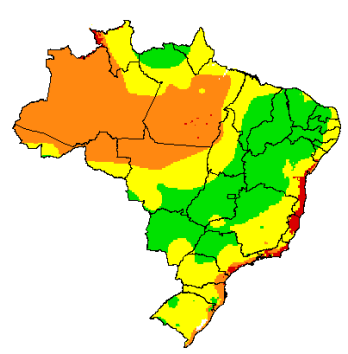

Fevereiro

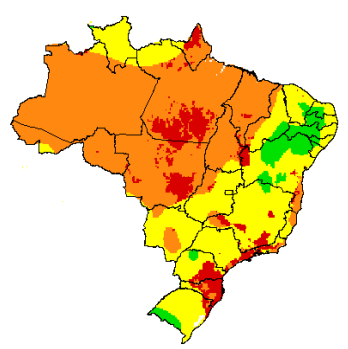

Maio

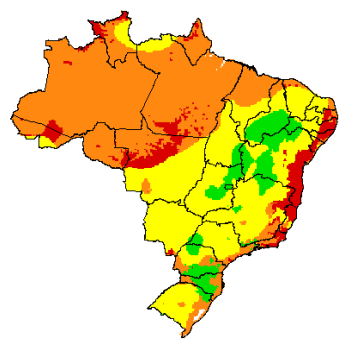

Agosto

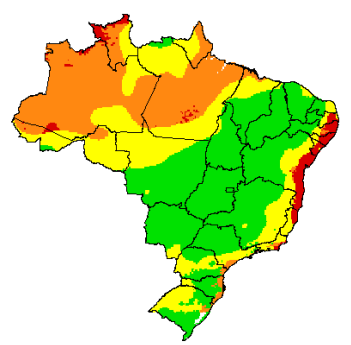

Novembro

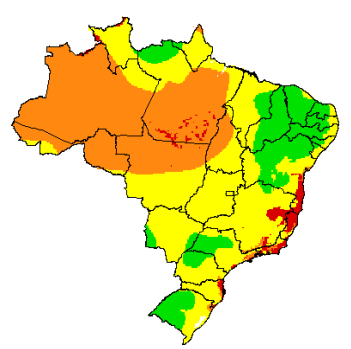

Março

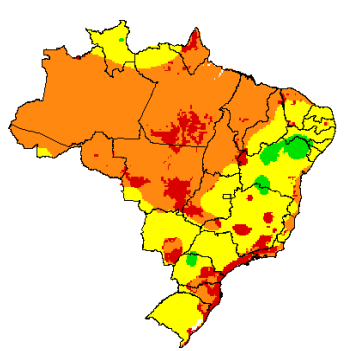

Junho

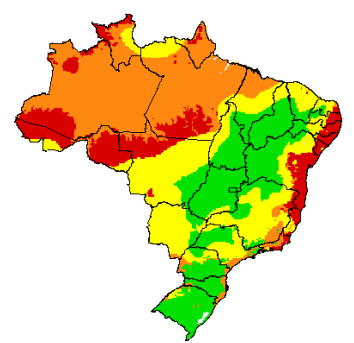

Setembro

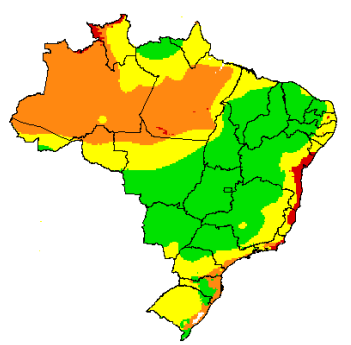

Dezembro

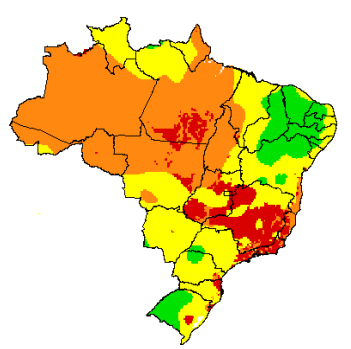

Figura 1. Distribuição espaço temporal das classes de favorabilidade climatica a Amphobotrys ricini (mofo cinzento da mamona) no Brasil. $1=$ altamente favorável; $2=$ favorável; 3 = relativamente favorável; 4 = desfavorável.

Fonte: Moraes et al. (2009).

Áreas classificadas como relativamente favoráveis encontram-se em maiores proporções nas regiões nordeste, sudeste e sul do país, o que sugere que nestas regiões devam ser empregadas medidas de manejo do mofo cinzento. As maiores porcentagens de áreas classificadas como desfavoráveis à ocorrência do mofo cinzento concentram-se na região nordeste, centro-oeste e em algumas partes da região sul e sudeste.

Houve variações da distribuição da doença quanto aos meses do ano, sendo que o 
período compreendido entre dezembro e junho foi determinado com maior potencial deestabelecimento e desenvolvimento do mofo cinzento da mamona. Tal fato se deve principalmente pela ocorrência de alta umidade relativa do ar, proporcionada pela alta precipitação. Já o período de maior desfavorabilidade a ocorrência do mofo cinzento foi de julho a outubro. Desta forma, a escolha da época de plantio da mamona deve ser feita de modo que a floração ocorra em condições climáticas desfavoráveis ao mofo cinzento.

As regiões com potencial para áreas desfavoráveis a ocorrência do mofo cinzento estão localizadas no nordeste, centro-oeste, sul, e sudeste (exceto parte do litoral brasileiro). Estas regiões são as maiores produtoras de mamona do país ou vem apresentando grande expansão desta cultura nos últimos anos, ambas possuindo grande potencial para o cultivo da mamona. A região nordeste é a maior produtora de mamona do Brasil. Em nível nacional o Estado da Bahia destaca-se como o principal produtor, seguido por São Paulo.

É importante salientar que o desenvolvimento da doença em determinada condição climática pode sofrer variações dependendo da variabilidade das populações do patógeno existente. Em determinadas regiões ou épocas do ano, as condições climáticas que favorecem o patógeno podem ocorrer em menor escala, restringindo a sua ocorrência e desenvolvimento. Para o manejo do mofo cinzento o plantio em áreas desfavoráveis a doença é uma alternativa promissora, pois a mamona é uma cultura com grande capacidade adaptativa às diferentes condições edafoclimáticas, sendo explorada comercialmente entre as latitudes $40^{\circ} \mathrm{N}$ e $40^{\circ} \mathrm{S}$.

\section{CONCLUSÃO}

A cultura da mamona tem grande potencial de aumento de áreas de cultivo no Brasil. O mofo cinzento é uma doença de grande importância econômica por afetar diretamente a produção de óleo da mamoneira. Desta forma, para o estabelecimento de um programa adequado de manejo fitossanitário da doença é imprescindível que se busquem alternativas viáveis tais como a incorporação de técnicas de manejo, que assegure uma melhor condição de produção para todos os elos da cadeia produtiva. $\mathrm{O}$ zoneamento climático do mofo cinzento da mamona apresenta-se como uma alternativa promissora a ser integrada no programa de manejo desta doença. 


\section{REFERÊNCIAS}

ARAÚJO, A.E.; SUASSUNA, N.D.; COUTINHO, W.M. Doenças e seu manejo. In: AZEVEDO, D.M.P.; BELTRÃO, N.E.M. (Org.). O agronegócio da mamona no Brasil. 2 ed. Brasília - DF: Embrapa Informação Tecnológica, 2007, v.1, p.283-303.

BALARDIN, R.S.et al. Influência do fósforo e do potássio na severidade da ferrugem da soja Phakopsora pachyrhizi. Fitopatologia Brasileira, v.31, n.5, p.462-467, 2006.

BATISTA, F.A.S.et al. Avaliação da resistência de genótipos de mamoneira Ricinus communis L. ao mofo cinzento causado por Botrytis ricini Godfrey. Campina Grande: Embrapa Algodão, 1998. 5p.

BELTRÃO, N.E.M.et al. Zoneamento e época de plantio da mamoneira para o nordeste brasileiro com aptidão sem restrições. Campina Grande: Embrapa Algodão, 2003.

DATNOFF, L.E.; ELMER, W.H.; HUBER, D.M. (Org.). Mineral nutrition and plant disease: American Phytopathological Society, 2007, v.1, p.57-78.

FERNANDES, C.D.; PEREIRA, F.A.R.; SHEEREN, B.R. Intensidade de doenças em cultivares de mamona cultivadas em diferentes arranjos populacionais. Fitopatologia Brasileira, Fortaleza, v.31, suplemento, p.226, 2006.

FREIRE, E.C.; LIMA, E.F.; ANDRADE, F.P. Melhoramento Genético. In: AZEVÊDO, D.M.P.; LIMA, E.F. (Ed.). O agronegócio da mamona no Brasil. Brasília: Embrapa Algodão. p.229-256, 2001.

FREIRE, R.M.M.et al. Avaliação da qualidade do óleo de mamona de diferentes genótipos. In: CONGRESSO BRASILEIRO DE MAMONA, 2. 2006, Aracaju. Anais... Aracaju-SE, 2006. 1 CD ROM.

GODFREY, G.H. Gray mold of castor bean. Journal of Agricultural Research, Washington, v.23, n.9, p.679-716, 1923.

HENNEBERT, G.L. Botrytis and Botrytis-like genera. Persoonia, Leiden, v.7, n.2, p.183204, 1973.

HOLCOMB, G.E.; JONES, J.P.; WELLS, D.W. Blight of prostrate spurge and cultivated poinsettia caused by Amphobotrys ricini. Plant Disease, St. Paul, v.73, n.1, p.74-75, 1989.

LIMA, E.F.; SOARES, J.J. Resistência de cultivares ao mofo cinzento causado por Botrytis ricini. Fitopatologia Brasileira, Brasília, v.15, n.1, p.96-97, 1990.

LIMA, E.F.; ARAÚJO, A.E.; BATISTA, F.A.S. Doenças e seu controle. In: AZEVEDO, D.M.P.; LIMA, E.F. (Eds.). O agronegócio da mamona no Brasil. Brasília: Embrapa Informação Tecnológica, 2001. p.191-212.

MASSOLA Jr., N.S.; BENDENDO, I.P. Doenças da Mamoneira (Ricinus communis). In: KIMATI, H.et al. (Eds.). Manual de fitopatologia: doenças das plantas cultivadas. 4. ed. São Paulo: Agronômica Ceres, 2005. v.2, p.445-447. 
MAPA. AGROFIT - sistema de agrotóxicos fitossanitários. Brasília: Ministério da Agricultura, Pecuária e Abastecimento, 2009. Disponível em:

<http://extranet.agricultura.gov.br/agrofit_cons/principal_agrofit_cons>. Acesso em: 08 mar. 2009.

MELHORANÇA, A.L.; STAUT, L.A. Indicações técnicas para a cultura da mamona em Mato Grosso do Sul. Dourados: Embrapa Agropecuária Oeste, 2005. 62p.

MORAES, W.B.et al. Zoneamento das áreas de risco a ocorrência do mofo cinzento da mamona no Brasil. In: ENCONTRO LATINO AMERICANO DE INICIAÇÃO CIENTÍFICA, 13. São José dos Campos, 2009, p.1-6.

NEW, M.; LISTER, D.; HULME, M.; MAKIN, I. A high-resolution data set of surface climate over global land areas. Climate Research, v.21, n.1, p.1-25, 2002.

ORELLANA, R.G.; THOMAS, C.A. Nature of predisposition of castorbeans to Botrytis. I. Relation of leachable sugar and certain other biochemical constituents of the capsule to varietal susceptibility. Phytopathology, v.52, n.6, p.533-538, 1962.

POLETINEM, J.P.et al. Avaliação de fungicidas para tratamento de sementes de mamona (Ricinus communis L.). In: CONGRESSO BRASILEIRO DE MAMONA, 2. 2006, Aracaju. Anais... Aracaju-SE. 2006. 1 CD ROM.

SILVA, A.P. Intensidade do mofo-cinzento (Amphobotrys ricini (Buchw.) Hernnebert) em linhagens de mamoneira (Ricinus communis $\mathbf{L}$.) cultivadas no estado de Alagoas e influência da adubação fosfatada na intensidade da doença nas cultivares Nordestina e Paraguaçu. 2007. 63 f. Dissertação (Pós-Graduação/Produção Vegetal) - Universidade Federal de Alagoas, Rio Largo. 